\section{Coiled Cathode Oxygen Polarograph}

Blood oxygen tension $\left(P_{\mathrm{O}_{\mathrm{s}}}\right)$ may be measured polarographically by shielding the cathode with a membrane ${ }^{1}$. Existing electrodes have two types of cathode, large and small. The large cathode of 1-2 $\mathrm{mm}$ diameter passes a current of 1-2 $\mu \mathrm{mmp}$ at a $P_{\mathrm{O}_{2}}$ of $150 \mathrm{~mm}$ mercury. Unfortunately reduction at the cathode produces a local zone of oxygen depletion and a steady reading can only be obtained by vigorous stirring $^{2}$. Stirring inevitably requires a rather large cuvette and a blood sample which is too large for repeated estimations on the infant and small experimental animal.

The small eathode, $40 \mu$ in diameter, is protected from zonal oxygen depletion by diffusion within the blood. The current passed is reduced to a twentieth of that from the larger cathode and requires expensive screened equipment for its measurement.

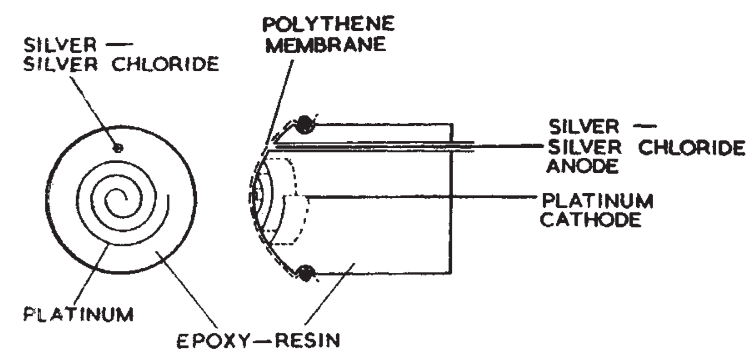

Fig. 1. Constructional details of the electrode

We have constructed an electrode in which the cathode takes the form of a spiral of platinum $40 \mu$ thick. It is embedded in epoxy resin and one edge is exposed by turning and grinding (Fig. 1). In this way we have obtained the area and current of a large cathode which is sufficiently dispersed to avoid zonal oxygen depletion without stirring (Fig. 2). This combination of the advantages of the two previous types of cathode enables cuvettes to be at least as small as $0.2 \mathrm{ml}$. without the constructional difficulties of stirring, and the current may be measured satisfactorily on a laboratory mirror galvanometer.

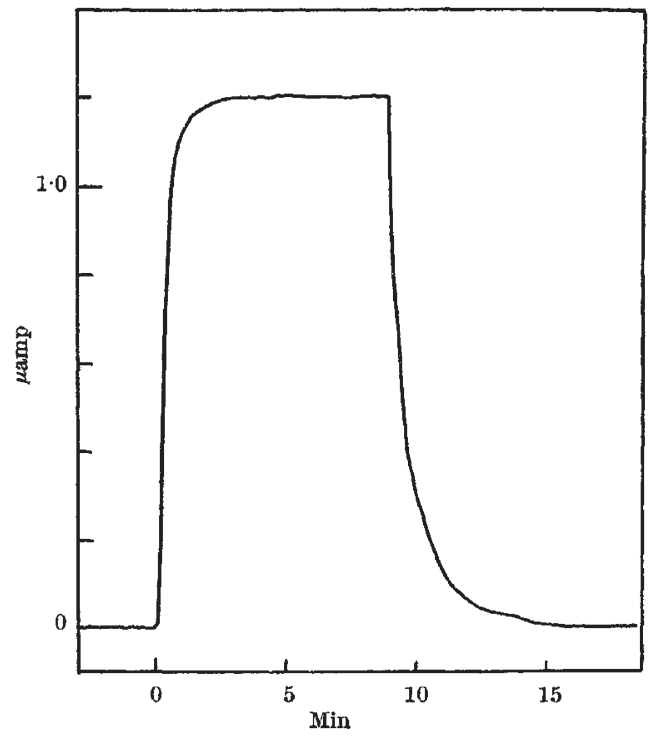

Fig. 2. Response of the electrode shown in Fig. 1. Air-equilibrated water was introduced into the cuvette at zero time and left un-
The response of this prototype electrode is rather slower than the Clark cell. This may be due to the solubility of oxygen in the epoxy resin. Glass may be a more suitable material for supporting the electrode. R. A. Butler

J. F. NUNN S. ASKILI

Research Department of Anæsthetics,

Royal College of Surgeons of England, Lincoln's Inn Fields, London, W.C.2.

${ }^{1}$ Clark, I. C., Trans. Amer. Soc. Art. Int. Org., 2, 41 (1956). ${ }^{2}$ Severinghaus, J. W., and Bradley, A. F., J. App. Physiol., 13, 515

\section{HFMATOLOGY}

\section{Comparative Metabolism of Hæmoglobins $A$ and $F$ in Thalassæmia}

INQUIRY into the comparative metabolic behaviour of the various normal and abnormal types of hæmoglobin seems likely to yield important knowledge about the pathogenesis of inherited disorders of hæmoglobin synthesis. The following study is submitted as a preliminary report which demonstrates a difference in the metabolism of hæmoglobins $A$ and $\mathbf{F}$ in a patient with thalassæmia intermedia.

The patient was a 33-year-old male with an established anæmia at a hæmoglobin level of $9 \cdot 0$ g per $100 \mathrm{ml}$. The spleen was intact. He has not required transfusions. Red cell morphology was typical for thalassæmia. Chromium-51 red cell survival was only slightly shortened (half-life 23 days). His hæmoglobin composition was 36 per cent $F, 5.9$ per cent $A_{2}$, and the remainder $\mathrm{A}$.

Two hundred $\mu \mathrm{c}$. of $\alpha^{-14} \mathrm{C}$-glycine were given intravenously in a single dose. Blood samples were drawn periodically for 122 days. The separation of hæmoglobins $\mathrm{A}, \mathrm{F}$, and $\mathrm{A}_{2}$ was done ehromatographically, using an initial separation on 'Amberlite $C G 50$ ' (ref. 1), followed by additional purification of the $\mathbf{F}$ on carboxymethylcellulose ${ }^{2}$. The samples were concentrated to small volumes by ultra-filtration, dialysed against water, and lyophilized. Radioactivity of the weighed samples was determined by liquid scintillation counting after combustion to ${ }^{14} \mathrm{CO}_{2}$ by modification of the Schoeniger technique ${ }^{3}$.

The results (Fig. 1) demonstrate a clear difference in the metabolism of hæmoglobins A and F. During the initial period of the curves, the specific activity of A rises to 1.3 times that of $\mathrm{F}$. In addition, hæmoglobin $A$ is seen to have the shorter mean life-span ( 73 days

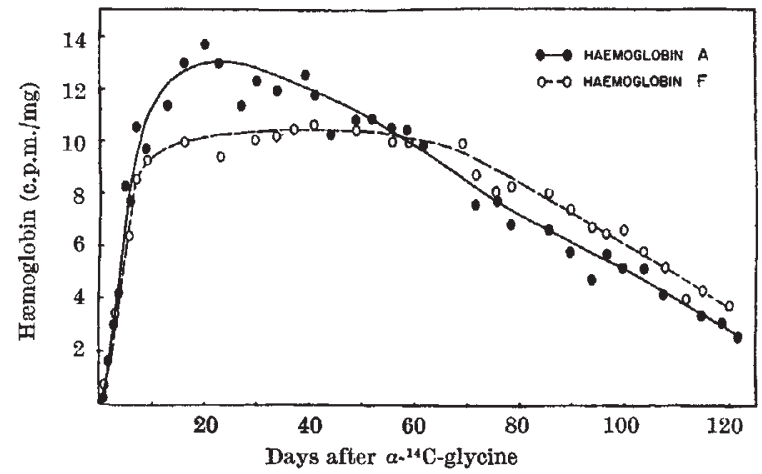

Fig. 1. Comparison of the specific activities of hæmoglobins $A$ and $F$ during a period of 122 days following an intravenou 